\title{
Analisa Kegagalan Poros Pompa Centrifugal Multistage (GA101A) Sub Unit Sintesa Urea PT. Petrokimia Gresik
}

\author{
Angga Setiawan, dan Witantyo \\ Jurusan Teknik Mesin, Fakultas Teknologi Industri, Institut Teknologi Sepuluh Nopember (ITS) \\ Jl. Arief Rahman Hakim, Surabaya 60111 Indonesia \\ e-mail:witantyo@me.its.ac.id
}

\begin{abstract}
Abstrak-Amonia Feed Pump GA101A merupakan pompa jenis centrifugal multistage dan merupakan salah satu critical equipment pada pabrik urea PT. Petrokimia Gresik. Kegagalan yang terjadi pada pompa GA101A adalah patahnya poros. Patah poros pompa dianalisa dengan melalui beberapa tahapan, yaitu pengamatan makroskopis, melakukan pemodelan CAD, kemudian melakukan analisa Finite Element. Analisa thermal expansion yang dilakukan yakni dengan membandingkan material ring sebelum dan sesudah modifikasi serta mengetahui thermal expansion yang terjadi pada poros. Dari analisa didapatkan mekanisme yang menyebabkan poros pompa GA101A patah, yaitu vibrasi tinggi pada pompa yang menyebabkan gesekan dan kenaikan temperatur melebihi temperatur kerja pompa. Temperatur akibat gesekan menyebabkan ekspansi material kedua komponen, sehingga ring mengunci poros hingga akhirnya patah. Langkah preventif dari hasil analisa adalah memperbesar clearance poros-ring sebesar $0.40 \mathrm{~mm}$ tanpa mengganti jenis material, yakni Stainless Steel 304, sedangkan jika dengan material Stainless Steel 410 clearance minimal yang dibutuhkan adalah sebesar $0.35 \mathrm{~mm}$.
\end{abstract}

Kata Kunci-Centrifugal Multistage Pump, Finite Element Analysis, Thermal expansion

\section{PENDAHULUAN}

$\mathrm{P}$ ETROKIMIA Gresik merupakan salah satu perusahaan pupuk terbesar di Indonesia yang berlokasi di Gresik, Jawa Timur. Untuk menunjang produksi, secara keseluruhan PT. Petrokimia Gresik terbagi menjadi tiga pabrik, yakni Pabrik 1 memproduksi amoniak, urea dan ZA, Pabrik 2 memproduksi pupuk fosfat dan phonska serta Pabrik 3 yang memproduksi kalium sulfat, asam sulfat dan asam fosfat. Pabrik 1 memiliki peran penting secara keseluruhan, karena beberapa hasil produksinya merupakan bahan baku untuk proses di pabrik 2 dan 3.

Produksi urea di Pabrik 1 memiliki kapasitas sebesar 1400 tons per hari atau lebih tepatnya 460.000 tons dalam setahun. Dalam proses produksinya, perusahaan sering menghadapi berbagai permasalahan teknis terkait dengan perawatan peralatan, baik static maupun rotating equipment. Perusahaan telah menerapkan metode perawatan preventif dan prediktif yakni terlihat dengan adanya jadwal perawatan ringan dan berat serta pengecekan vibrasi secara berkala yang dilakukan oleh Departemen Pemeliharaan dan Inspeksi Teknik. Namun metode perawatan yang ada dinilai masih belum optimal karena kegagalan yang terjadi pada peralatan tidak pernah dilakukan studi lebih lanjut untuk diketahui akar penyebab kerusakan, sehingga kerusakan yang sama tidak dapat diantisipasi.
Amonia Feed Pump GA 101A merupakan salah satu critical equipment, yakni apabila pompa tersebut mengalami breakdown, maka produksi tidak dapat terjadi. Pompa GA101A sendiri merupakan pompa jenis centrifugal multistage. Sesuai dengan teori, pompa multistage memiliki head yang tinggi yang dibutuhkan pada proses feeding amonia ke reaktor, dimana pada sisi suction pompa GA101A ini terhubung langsung dengan sisi discharge Amonia Boost Pump GA103.

Kegagalan yang terjadi pada pompa GA101A adalah patahnya poros (shaft fracture) pada tanggal 29 Februari 2016, pada hari pertama pompa beroperasi setelah Turn Arround (TA). Indikasi awal adalah terjadinya kenaikan trend vibrasi pada bagian bearing outboard sejak bulan November 2015, dan atas saran dari Departemen Inspeksi Teknik dilakukan reallignment dan menyesuaikan putaran operasionalnya, sehingga mampu bertahan hingga proses TA. Saat proses TA selesai, pompa GA101A dioperasikan untuk proses feeding, namun pompa hanya mampu beroperasi selama 11 jam, yakni mulai pukul 08.00 WIB hingga pukul 19.00 WIB pompa dinyatakan macet. Pengamatan awal yang dilakukan, yakni secara visual dari hasil patahan, menunjukkan bahwa letak shaft fracture pada bagian balance sleeve yang juga ter-assembling dengan stage piece-balance sleeve. Kondisi stage piecebalance sleeve terkikis lebih dari separuh dan lengket dengan balance sleeve.

Hipotesa yang dilakukan oleh mekanik di lapangan, pompa diduga kehilangan flow pada sisi suction karena hasil kerusakan pompa menunjukkan bahwa bagian discharge mendorong ke sisi kopling atau sisi suction akibat gaya yang tidak berimbang. Dugaan tersebut dinilai masih lemah karena hipotesa tersebut belum mengarah pada akar permasalahan. Dengan mengacu pada studi lapangan bahwa patah yang terjadi pada poros pompa GA101A adalah diduga karena patah lelah (fatigue fracture). Patah lelah yang terjadi adalah akibat beban dinamis yang terjadi pada pompa, yakni torsion [3]. Akan tetapi, letak dari patahan berada pada outboard, dimana tidak berhubungan langsung dengan couple steam turbine, sehingga diperkirakan memiliki faktor lain. Faktor lain yang memungkinkan adalah terjadinya thermal expansion material poros dan ring di sekitar patahan. Clearance yang tidak mencukupi untuk ruang muai material menyebabkan ring mengunci poros pada saat beroperasi dan berakibat patah. 


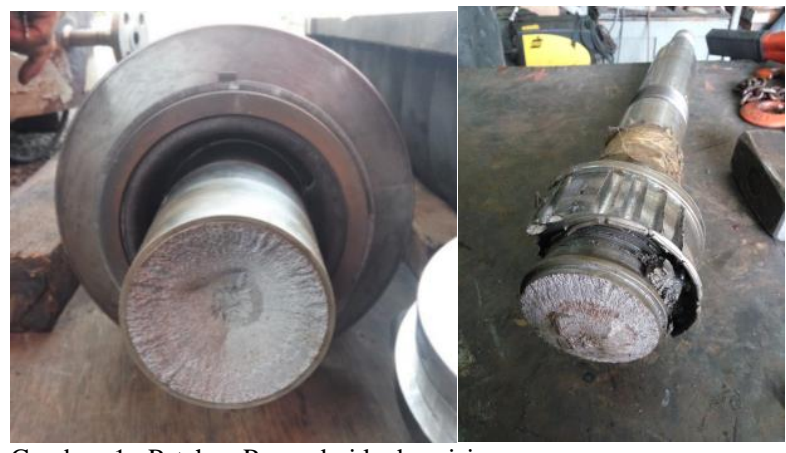

Gambar. 1. Patahan Poros dari kedua sisi

Sebagai tindakan antisipasi agar kegagalan yang sama tidak terulang, maka perlu dilakukan tindakan proactive, yakni dengan melakukan analisa kegagalan (failure analysis). Untuk mengetahui secara detil proses terjadinya patahan pada poros pompa GA101A maka dilakukan pendekatan model dan simulasi sistem. Pemodelan dilakukan dengan mengacu pada kondisi nyata di lapangan, yakni menyesuaikan ukuran spesimen dan parameter lainnya agar didapatkan model yang mendekati. Hasil dari simulasi didapatkan visualisasi bagaimana mekanisme terjadinya shaft fracture serta faktorfaktor penyebabnya.

\section{TINJAUAN PUSTAKA}

\section{A. Pembebanan pada Poros}

Beban yang diterima oleh poros antara lain adalah torsi, berat komponen dan gaya hidrolik radial maupun aksial. Dalam merancang suatu poros, defleksi maksimal yang diperbolehkan, lama pakai dan letak pembebanan harus diperhatikan, begitu pula dengan kecepatan kritisnya.

Poros biasanya diproporsikan untuk mengatasi tegangan yang timbul pada saat pompa dijalankan dengan cepat. Jika pompa digunakan untuk cairan yang panas, poros dirancang untuk mengatasi tegangan yang muncul ketika pompa mulai dingin tanpa adanya pemancingan terlebih dahulu.

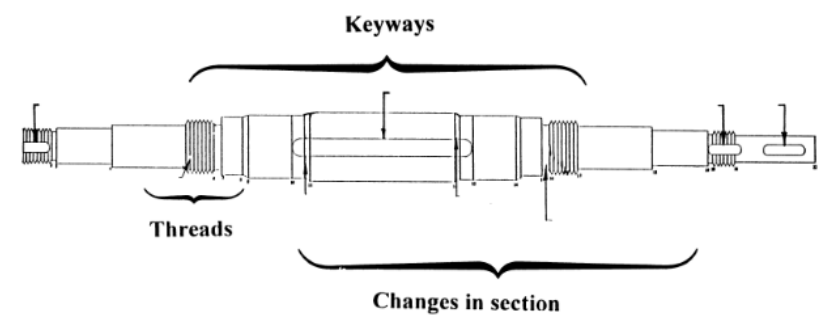

Gambar 2. Konsentrasi Tegangan pada Poros [4]

Gambar 2 menunjukkan letak konsentrasi tegangan pada poros dimana patah lelah mungkin bermula. Area paling umum menjadi awal patahan adalah konsentrasi tegangan yang terjadi pada radius terkecil pada keyway dan sudut-sudut yang tajam pada area penampang yang melintang pada poros. Letak konsentrasi tegangan ini harus dihindari ketika mendesain poros.

Baja (kecuali baja tahan karat) memiliki batas kelelahan di mana tegangan di bawah perambatan patah lelah tidak akan terjadi tanpa adanya gaya yang berulang [1]. Oleh karena itu, adanya konsentrasi tegangan menurunkan batas tegangan yang diperbolehkan pada poros di titik itu, dan membuatnya semakin rentan terhadap kelelahan. Sementara itu baja tahan karat memiliki batas ketahanan, misalnya material tersebut mampu menahan gaya berulang secara terbatas sebelum mengalami kegagalan dikarenakan kelelahan.

\section{B. Failure Analysis}

Analisis kegagalan (Failure Analysis) adalah langkahlangkah pemeriksaan kegagalan atau kerusakan pada suatu komponen yang mencakup situasi dan kondisi kegagalan atau kerusakan tersebut, sehingga dapat ditentukan penyebab dari kegagalan/kerusakan yang terjadi pada komponen tersebut [2]. Analisis kegagalan mempunyai tujuan sebagai berikut:

1. Menemukan penyebab utama kegagalan

2. Menghindari kegagalan/kerusakan yang sama dimasa yang akan datang dengan melakukan langkah-langkah penanggulangan

3. Sebagai bahan pengaduan teknis terhadap pembuat komponen

4. Sebagai langkah awal untuk perbaikan kualitas komponen tersebut

5. Sebagai penentuan kapan waktu perawatan (maintenance) dilakukan.

\section{Identifikasi Jenis Kegagalan}

Kegagalan dapat didefinisikan sebagai kerusakan yang tidak wajar atau rusak sebelum waktunya. Adapun penyebab utama kegagalan dapat dikelompokkan sebagai berikut:

1. Kesalahan dalam disain

2. Kesalahan dalam pemilihan material

3. Kesalahan dalam proses pengerjaan

4. Kesalahan dalam pemasangan/perakitan

5. Kesalahan operasional

6. Kesalahan perawatan (maintenance)

Secara umum komponen dapat dikatakan gagal apabila masuk dalam kriteria sebagai berikut:

1. Komponen tidak dapat beroperasi atau tidak dapat digunakan sama sekali

2. Komponen dapat digunakan tetapi umur pakainya terbatas (tidak sesuai dengan umur pakai yang dikehendaki)

Komponen mengalami kelainan dan dapat membahayakan bila digunakan.

\section{METODE PENELITIAN}

\section{A. Alur Penelitian}

Alur penelitian bertujuan untuk membuat peneltian lebih terstruktur dan sistematis. Dalam sub bab ini akan dibahas bagaimana urutan langkah penelitian serta metode-metode yng dipergunakan selama penelitian. Diawali dari tahap investigasi lapangan hingga didapatkan sebuah hasil yaitu rekomendasi yang tepat untuk mengantisipasi kerusakan yang sama di masa yang akan datang. Untuk lebih jelasnya dapat dilihat pada penjelasan di bawah ini.

1. Studi Lapangan dan Identifikasi Permasalahan

Pada tahap studi lapangan, dilakukan pengamatan terhadap beberapa peralatan pabrik yang sedang dalam kondisi breakdown, ataupun merupakan komponen kritis dari pabrik. Tersedia beberapa pilihan peralatan yang sedang breakdown, namun pompa GA101A memiliki permasalahan yang lebih 
kompleks akibat kegagalan poros (shaft fracture) dan merupakan salah satu komponen kritis yang ada di pabrik. Tahap ini meliputi mempelajari secara detail desain pompa, fungsi dan sistematika kerja pompa, spesifikasi pompa, serta pengamatan visual dari kerusakan pompa yang ada yakni pada patahnya poros.

\section{Pengumpulan Historical Data Pompa GA101A}

Historical data dikumpulkan, mulai dari data vibrasi, work order yang dilakukan oleh pihak mekanik, spesifikasi pompa, spesifikasi bahan komponen poros. Dari historical data, dapat dilihat kerusakan apa saja yang pernah terjadi pada pompa selama operasinya.

\section{Studi Literatur}

Studi Literatur merupakan tahap mempelajari referensireferensi yang ada, baik handbook maupun jurnal. Studi literatur berguna untuk mendukung penulis melakukan analisa kerusakan yang terjadi serta mengetahui penelitian-penelitian terdahulu yang telah dilakukan oleh peneliti lain.

4. Melakukan Pengamatan Makroskopis

Pengamatan secara makroskopis berguna untuk melihat bentuk dan pola patahan yang terjadi pada poros pompa. Pengamatan ini dilakukan dengan melakukan fotografi secara close up pada penampang patahan.

5. Analisa thermal expansion ring dan poros

Tahap ini berguna untuk mengetahui bagaimana thermal expansion memiliki pengaruh besar dalam proses patahnya poros pompa GA101A. Selain itu dengan analisa ini dapat membandingkan material dan clearance ring hasil modifikasi, apakah memiliki pengaruh besar dalam patah poros.

\section{Alternatif Penyelesaian}

Analisa dengan menggunakan Finite Element dilakukan agar dapat diketahui alternatif penyelesaian yang ada. Alternatif penyelesaian yang dapat dicapai adalah perubahan desain, melakukan penyesuaian beban operasi, deteksi dini kegagalan serta penggantian jenis material.

7. Kesimpulan dan Saran

Tahap akhir dari penelitian ini didapatkan sebuah kesimpulan akan penyebab kerusakan yang terjadi. Selain itu, setelah ditemukan penyebab kerusakan yang pasti, maka akan didapatkan sebuah rekomendasi kepada perusahaan khususnya PT. Petrokimia Gresik untuk menghindari kerusakan dengan modus yang sama di masa yang akan datang.

\section{B. Finite Element Analysis}

Dalam menganalisa menggunakan finite element, terdapat beberapa langkah-langkah yang dilakukan, yaitu:

1. Desain geometri 3D

Pembuatan desain geometri tiga dimensi dari komponen poros dengan mengacu pada dimensi aktual karena dari pihak manufacturing tidak memberikan dimensi orisinil.

2. Import CAD ke Finite Element Software

Setelah desain tiga dimensi CAD selesai, maka tahap selanjutnya adalah mengimpor geometri ke Finite Element Software untuk dilakukan analisa lebih lanjut.

\section{Engineering Data}

Engineering data yang dimasukkan dalam software adalah data yang termuat dalam mechanical properties Stainless Steel $410 \mathrm{H}$ serta 304.

4. Meshing
Pada proses meshing ini ada beberapa metode pilihan yang bisa dipergunakan, salah satu metode yang akan dipergunakan dalam penelitian ini adalah Hex Dominant.

\section{Fixed Support dan Thermal Condition}

Pada tahap ini ditentukan posisi titik-titik pusat tegangan statis serta aplikasi thermal condition yang diberikan pada komponen ring dan poros.

6. Coordinate System

Pada langkah ini ditentukan koordinat system baru, karena untuk mengetahui ekspansi material secara radial, sehingga dipilih tipe cylindrical dengan axis $\mathrm{X}$ ke arah radial.

7. Solution

Tahap ini merupakan proses analisa untuk memperoleh hasil. Solution dilakukan jika pemodelan dan variable telah ditentukan

\section{ANALISA DAN PEMBAHASAN}

\section{A. Analisa Patahan}

Kerusakan yang terjadi pada pompa sentrifugal multistage GA101A adalah patahnya poros pompa yang terjadi setelah proses turn arround (TA) Januari-Februari 2016. Informasi ukuran geometri dari poros sendiri tidak diberikan oleh manufacturer, sehingga dilakukan pengukuran aktual pada poros yang ada. Bentuk poros dan posisi patahan yang terjadi dapat dilihat pada gambar 3, sedangkan foto patahan pada poros dapat dilihat pada gambar 4.

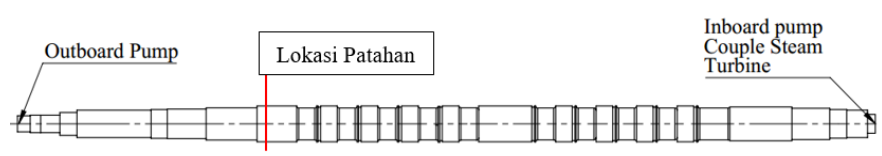

Gambar 3. Lokasi Patahan Poros

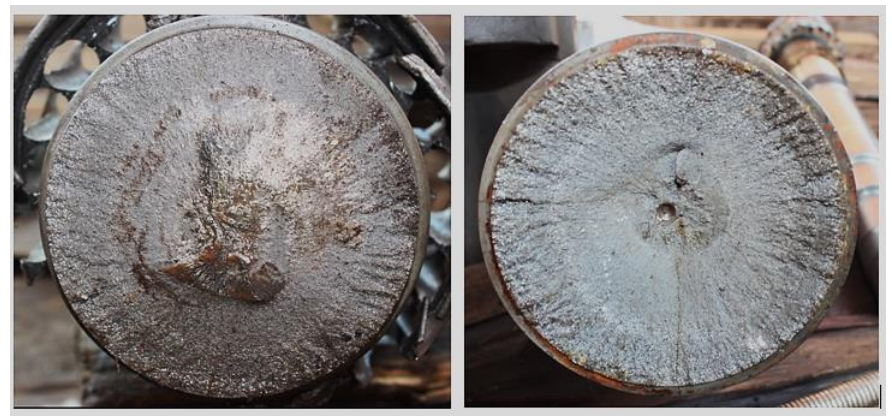

Gambar 4. Penampang Patahan Poros kedua sisi

Dari gambar 3 terlihat bahwa posisi patahan poros tidak berdekatan dengan couple steam turbine, sehingga dugaan akan patahan terjadi karena besarnya pengaruh torsi menjadi sangat lemah. Hipotesa selanjutnya mengacu pada terjadinya thermal expansion yang terjadi antara shaft dan ring yang berada dalam barrel cover. Hipotesa ini dipicu adanya informasi bahwa ring yang digunakan merupakan ring baru yang diganti pada saat proses Turn Arround (TA).

Mengacu pada gambar 6, spektrum warna yang terdapat pada patahan poros gambar 5 menunjukkan adanya pengaruh temperatur antara $1500-2700^{\circ} \mathrm{K}$ atau $1227-2427^{\circ} \mathrm{C}$, yang sangat jauh dari temperatur operasi pompa itu sendiri, yakni sebesar $40-60^{\circ} \mathrm{C}$. Temperatur tinggi ini disebabkan oleh gesekan yang 
terjadi antara komponen ring dan poros yang menimbulkan panas berlebih. Hasil simulasi thermal dapat dilihat pada sub bab selanjutnya.

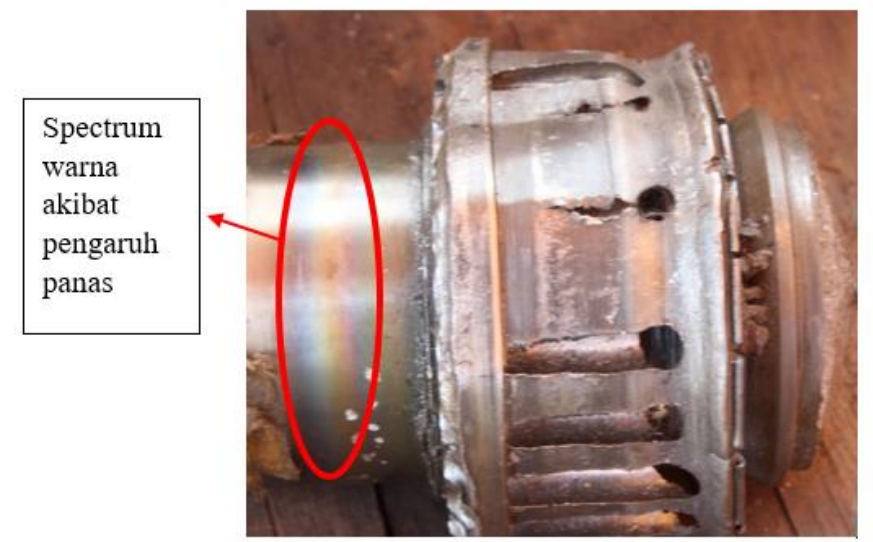

Gambar 5. Spektrum Warna pada Poros

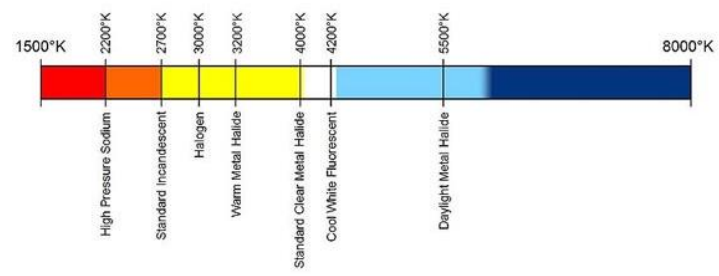

Gambar 6. Kelvin Temperature Chart [5]

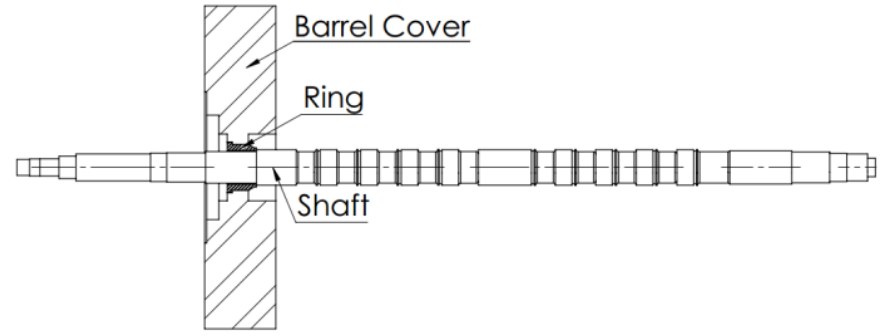

Gambar 7. Potongan Joint Shaft, Ring dan Barrel Cover

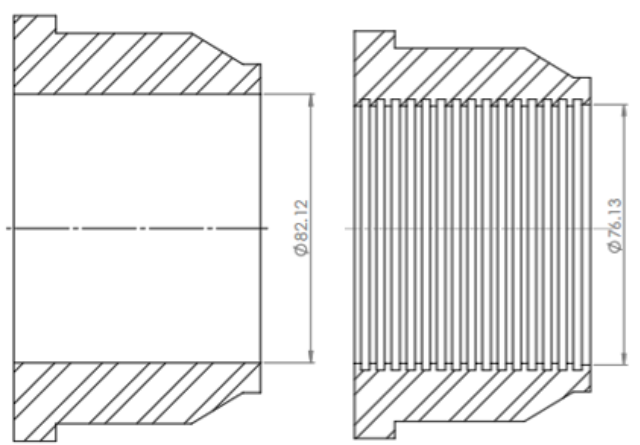

Gambar 8. Ring sebelum (kiri) dan sesudah (kanan) modifikasi

Dalam histori perawatan, terjadi modifikasi geometri ring dan poros akibat terjadi unbalance yang menyebabkan keausan pada ring. Modifikasi yang dilakukan pada ring berupa penambahan labirin pada inner diameter dan penggantian material dari stainless steel 410 menjadi 304 dikarenakan ketersediaan material yang ada. Clearance poros dan ring pada desain awal sebesar $0.165 \mathrm{~mm}$, akan tetapi setahun sebelum patahnya poros, clearance hasil pengukuran aktual poros dan ring adalah sebesar $2.12 \mathrm{~mm}$. Pada kegiatan turn around 2016 dilakukan pengurangan clearance hingga mendekati desain, yakni dari $2.12 \mathrm{~mm}$ menjadi $0.30 \mathrm{~mm}$ dengan melakukan pengurangan diameter poros dari $80 \mathrm{~mm}$ hingga menjadi 75,83 $\mathrm{mm}$, sedangkan ring pada gambar 8 dari inner diameter 82.12 $\mathrm{mm}$ menjadi $76.13 \mathrm{~mm}$. Langkah ini dilakukan karena poros yang bersinggungan dengan ring terjadi aus di beberapa sisi, sehingga dilakukan pengurangan diameter poros untuk meratakan diameter.

\section{B. Spesifikasi Material}

Tabel 1.

Physical and Mechanical Properties SS 410H

\begin{tabular}{ll}
\hline \hline Density & $7740 \mathrm{~kg} / \mathrm{m} 3$ \\
Coefficient of Thermal expansion & $0-649^{\circ} \mathrm{C}=11.6 \times 10^{-6} /$ \\
& ${ }^{\circ} \mathrm{C}$ \\
Zero Thermal Strain Reference Temperature & $22{ }^{\circ} \mathrm{C}$ \\
Young Modulus & $1.93 \times 10^{11} \mathrm{~Pa}$ \\
Poisson Ratio & 0.31 \\
Bulk Modulus & $1.693 \times 10^{11} \mathrm{~Pa}$ \\
Shear Modulus & $7.3664 \times 10^{10} \mathrm{~Pa}$ \\
Tensile strength & $620 \mathrm{MPa}$ \\
Compressive Yield Strength & $620 \mathrm{MPa}$ \\
Tensile Ultimate Strength & $830 \mathrm{MPa}$ \\
\hline \hline
\end{tabular}

Tabel 2.

Physical and Mechanical Properties SS 304

\begin{tabular}{ll}
\hline \hline Density & $8030 \mathrm{~kg} / \mathrm{m} 3$ \\
Coefficient of Thermal expansion & $0-315^{\circ} \mathrm{C}=17.3 \times 10^{-6} /$ \\
& ${ }^{\circ} \mathrm{C}$ \\
Zero Thermal Strain Reference Temperature & $22^{\circ} \mathrm{C}$ \\
Young Modulus & $1.93 \times 10^{11} \mathrm{~Pa}$ \\
Poisson Ratio & 0.29 \\
Bulk Modulus & $1.5317 \times 10^{11} \mathrm{~Pa}$ \\
Shear Modulus & $7.4806 \times 10^{10} \mathrm{~Pa}$ \\
Tensile strength & $215 \mathrm{MPa}$ \\
Compressive Yield Strength & $215 \mathrm{MPa}$ \\
Tensile Ultimate Strength & $505 \mathrm{MPa}$ \\
\hline \hline
\end{tabular}

\section{Finite Element Analysis}

\section{Thermal Load pada Poros}

Analisis thermal pada poros dilakukan dengan memberikan beban thermal secara menyeluruh pada bodi. Kemudian untuk pengambilan data, dilakukan dengan mengambil ekspansi maksimal pada titik joint poros dan ring. Simulasi thermal pada poros dapat dilihat pada gambar 9 hingga 11 dan hasil data ekspansi dapat dilihat pada tabel 4.

\section{Thermal Load pada Ring}

Simulasi Thermal load pada ring dilakukan pada dua jenis material yang berbeda namun dengan geometri yang sama. Keadaan ini mengacu pada keadaan sebelum dan sesudah modifikasi ring, untuk mengetahui bagaimana efek perbedaan material terhadap thermal expansion. Simulasi Thermal Load pada masing-masing material dapat dilihat pada gambar 12 hingga 15 dan data hasil analisa disajikan pada tabel 3 .

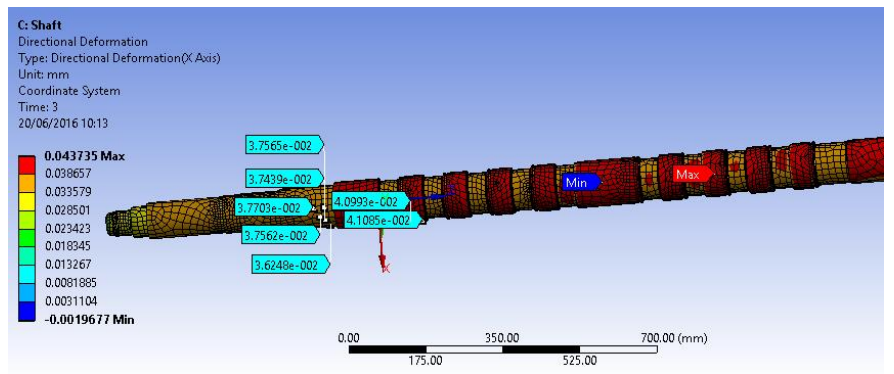

Gambar 9. Directional Deformation pada Poros 


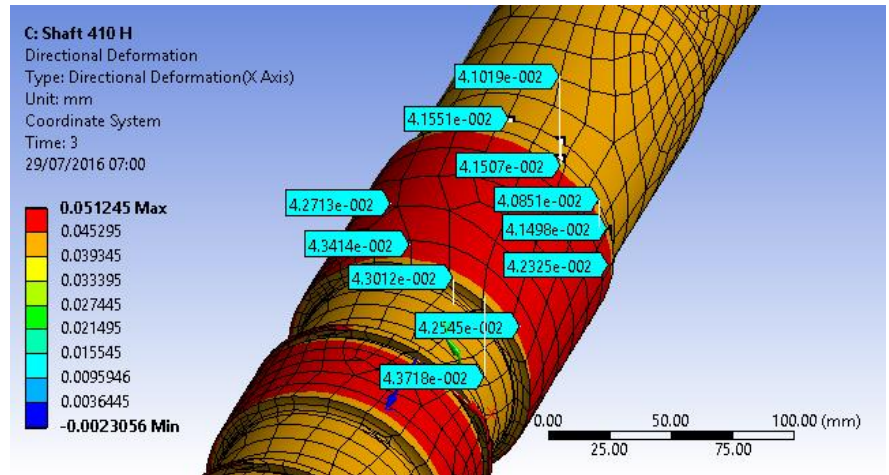

Gambar 10. Detail Ekspansi Thermal pada Joint ring dengan Temperatur akhir $100^{\circ} \mathrm{C}$

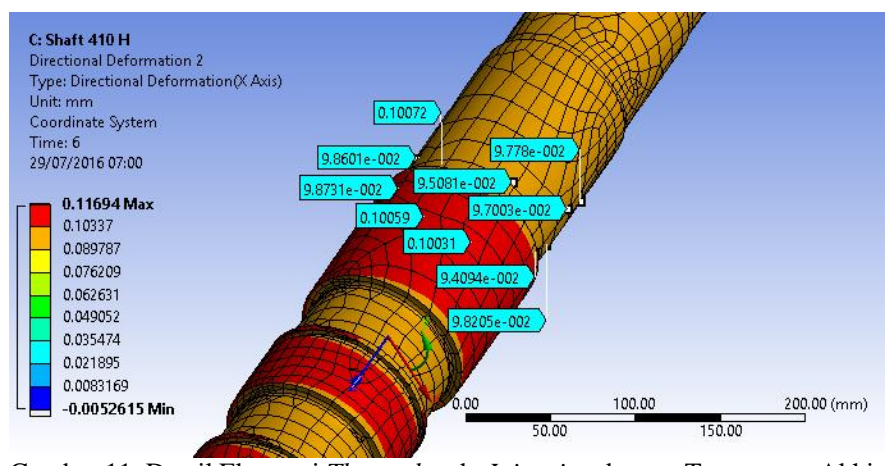

Gambar 11. Detail Ekspansi Thermal pada Joint ring dengan Temperatur Akhir $200^{\circ} \mathrm{C}$

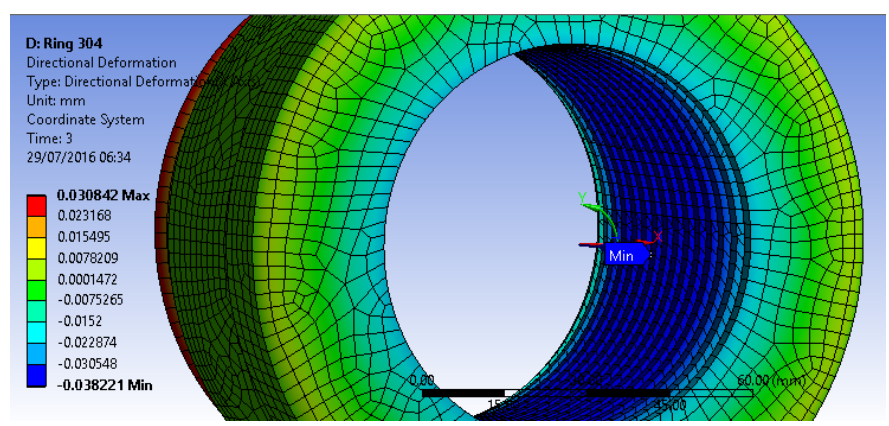

Gambar 12. Ekspansi Thermal Inner ring SS 304 Pada Temperatur Akhir $100^{\circ} \mathrm{C}$

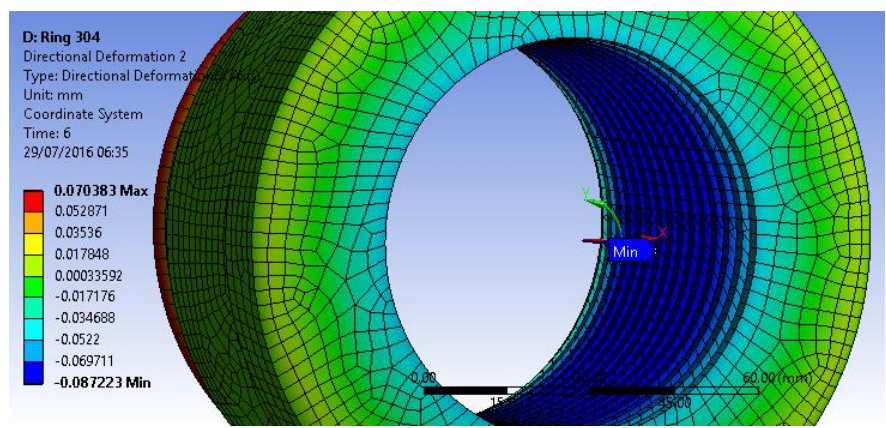

Gambar 13. Ekspansi Thermal Inner ring SS 304 Pada Temperatur Akhir $200^{\circ} \mathrm{C}$

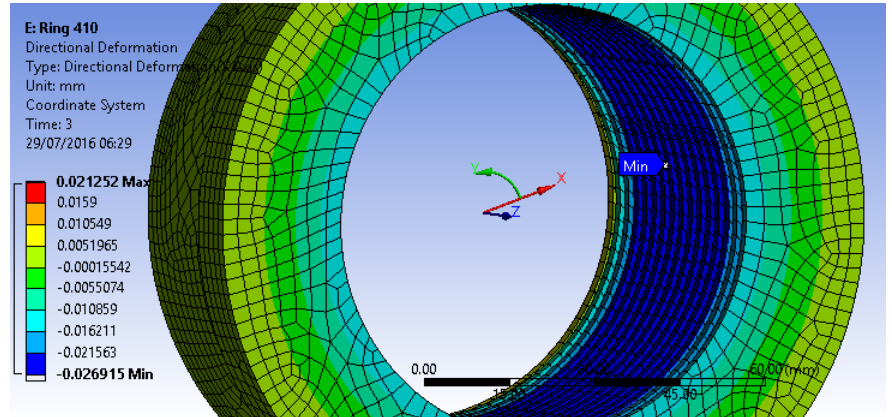

Gambar 14. Ekspansi Thermal Inner ring SS 410 Pada Temperature Akhir $100^{\circ} \mathrm{C}$

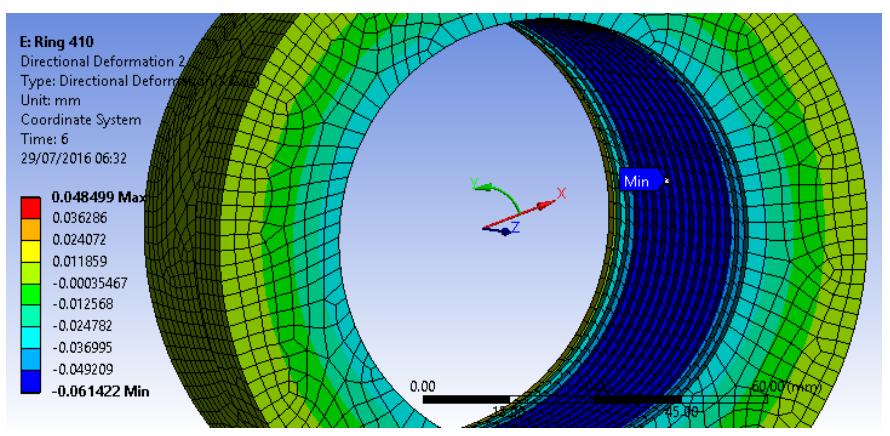

Gambar 15 Ekspansi Thermal Inner ring SS 410 Pada Temperatur Akhir $200^{\circ} \mathrm{C}$

Hasil simulasi thermal pada ring dan poros akan didapatkan seperti pada tabel dibawah ini.

Tabel 3.

Perbandingan Thermal expansion material ring

\begin{tabular}{ccccccc}
\hline \hline $\begin{array}{c}\text { Tempera- } \\
\text { tur }\end{array}$ & $\begin{array}{c}\text { Ekspan- } \\
\text { si Poros }\end{array}$ & Ring & $\begin{array}{c}\text { Ekspan- } \\
\text { si Ring }\end{array}$ & $\begin{array}{c}\text { Clea- } \\
\text { rance }\end{array}$ & $\begin{array}{c}\text { Total } \\
\text { Expan- } \\
\text { sion }\end{array}$ & $\begin{array}{c}\text { Sisa } \\
\text { Clea- } \\
\text { rance }\end{array}$ \\
\hline & & \multirow{2}{*}{304} & 0.0382 & 0.15 & 0.081918 & 0.068082 \\
$100^{\circ} \mathrm{C}$ & 0.04372 & & $\mathrm{~mm}$ & $\mathrm{~mm}$ & $\mathrm{~mm}$ & $\mathrm{~mm}$ \\
& $\mathrm{~mm}$ & \multirow{2}{*}{410} & 0.0269 & 0.15 & 0.070618 & 0.079382 \\
& & & $\mathrm{~mm}$ & $\mathrm{~mm}$ & $\mathrm{~mm}$ & $\mathrm{~mm}$ \\
& & 0.08722 & 0.15 & 0.18794 & -0.03794 \\
$200^{\circ} \mathrm{C}$ & 0.10072 & \multirow{3}{*}{304} & $\mathrm{~mm}$ & $\mathrm{~mm}$ & $\mathrm{~mm}$ & $\mathrm{~mm}$ \\
& $\mathrm{~mm}$ & \multirow{2}{*}{410} & 0.0614 & 0.15 & 0.16212 & -0.01212 \\
& & & $\mathrm{~mm}$ & $\mathrm{~mm}$ & $\mathrm{~mm}$ & $\mathrm{~mm}$ \\
\hline \hline
\end{tabular}

Hasil analisa finite element, mekanisme patahan yang terjadi karena thermal expansion pada poros dan ring yang melebihi batas clearance yang ada. Initial thermal load disebabkan oleh temperature kerja pompa itu sendiri sebesar $40-60^{\circ} \mathrm{C}$ dan pada kondisi tersebut masih tergolong aman. Namun, dengan adanya vibrasi tinggi pada poros pompa, maka gesekan akan selalu terjadi. Gesekan inilah yang akan menaikkan suhu ring, sehingga melebihi temperatur kerja pompa. Saat suhu mencapai sekitar $200^{\circ} \mathrm{C}$, gesekan akan semakin besar bahkan menurut spektrum warna pada poros, suhu mencapai sekitar $1200^{\circ} \mathrm{C}$ sebelum poros putus.

Vibrasi yang terjadi pada pompa diperkirakan diakibatkan oleh unbalance maupun misalignent. Unbalance muncul dari massa unbalance pada impeller pompa. Modal analysis pada poros pompa menunjukkan tidak terjadi resonansi, pada putaran operasi. Pada gambar 4.20 terdapat sepuluh natural frequency poros. Operasi poros sendiri pada putaran $6300 \mathrm{rpm}$ atau 105rps, sehingga apabila dicocokkan pada frekuensi natural poros, tidak terjadi resonansi karena frekuensi eksternal tidak ada yang mendekati frekuensi natural poros. 


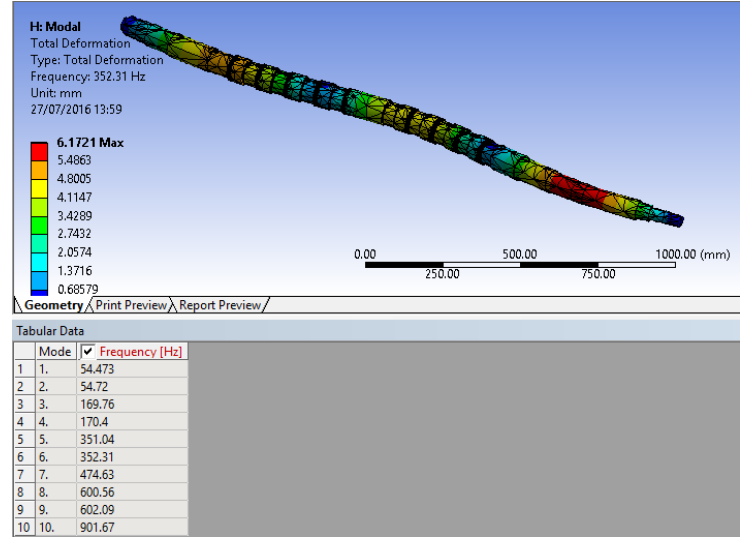

Gambar 16. Modal Analysis

Mengacu pada hasil analisa finite element, untuk menanggulangi thermal expansion material yang terjadi antara ring dan poros, maka rekomendasi yang dapat dilakukan adalah dengan mengubah besaran clearance antara kedua komponen tersebut. Clearance aman menurut hasil finite element analysis, dengan material ring Stainless Steel 304 dan temperatur $200^{\circ} \mathrm{C}$ adalah diatas $0.40 \mathrm{~mm}$, sehingga penggantian jenis material tidak diperlukan. Namun, apabila digunakan material Stainless Steel 410, clearance ring-poros minimal yang dibutuhkan adalah sebesar $0.35 \mathrm{~mm}$. Selain itu, apabila terjadi perbaikan pada pompa sehingga harus dilakukan pembongkaran, maka perlu dilakukan balancing setelah impeller terpasang pada poros, karena berpotensi adanya massa unbalance pada impeller yang dapat mengakibatkan munculnya vibrasi.

\section{KESIMPULAN}

Dari hasil analisa dan pembahasan pada penelitian ini dapat disimpulkan bahwa:

1. Penggantian jenis material ring, dari stainless steel 410 menjadi 304, menjadi salah satu faktor penyebab patahnya poros, karena jika ditinjau dari thermal expansion material, stainless steel 304 memiliki thermal expansion lebih tinggi daripada 410.

2. Vibrasi yang terdeteksi pada pompa merupakan akibat dari massa unbalance pada sudu-sudu pompa (impeller), karena setelah dilakukan modal analysis pada poros, antara frekuensi beban yang diberikan dengan frekuensi natural poros masih dalam kategori aman.

3. Vibrasi yang terdeteksi pada pompa menyebabkan komponen poros dan ring saling bergesekan, sehingga temperatur di sekitar komponen tersebut meningkat drastis. Dari hasil pengamatan, terlihat adanya spektrum warna disekitar patahan, yang merupakan indikasi terjadinya temperature berlebih. Mengacu pada Kelvin Temperature chart, temperatur pada area patahan dapat mencapai kisaran $1200-2700^{\circ} \mathrm{K}$

4. Berdasarkan simulasi, solusi yang dapat dilakukan adalah memodifikasi clearance ring dan poros, dengan minimal besarannya adalah $0.40 \mathrm{~mm}$ dengan material 304 yang ada, sedangkan apabila menggunakan material 410, maka minimal clearance ring-poros yang dibutuhkan adalah sebesar $0.35 \mathrm{~mm}$.

\section{UCAPAN TERIMA KASIH}

Penulis A.S. mengucapkan terima kasih kepada Ir. Witantyo, M.Eng.Sc, Dr. Eng. Sutikno, ST, MT, Indra Sidharta, ST, MSc dan Arif Wahyudi, ST, MT, PhD yang telah memberikan bimbingan selama proses pengerjaan penelitian ini.

\section{DAFTAR PUSTAKA}

[1] Akuan, Abrianto. 2007. Diktat Kuliah Kelelahan Logam. Jurusan Teknik Metalurgi. Universitas Jenderal Achmad Yani Bandung.

[2] ASM Handbook Committee. 2002, ASM Metals Handbook Vol. 11: Failure Analysis and Prevention. Ohio, USA: ASM International.

[3] ASM Handbook Committee. 2002, ASM Metals Handbook Vol. 19: Fatigue and Fracture. Ohio, USA: ASM International.

[4] Berndt, F.and Bennekom, A. Van., 2001. "Pump Shaft failures - A Compendium of Case Studies ", Engineering Failure Analysis 8 (2001) 135144

[5] Kelvin
Temperature 